\title{
Undifferentiated carcinoma of pancreas with osteoclastic giant cells along with PanIN in a diabetic female- A case report
}

\author{
Lakshmi Priya U $^{1}$, Noushad Babu PK ${ }^{2}$, Asiq Sideeque ${ }^{1}$ \\ ${ }^{1}$ Department of Pathology, Mes Medical College, Palachode P.O, Perinthalmanna, Kerala, India \\ ${ }^{2}$ Department of gasrosurgery, Alshifa hospital, Perinthalmanna, Kerala, India.
}

\section{Keywords:}

Osteoclastic;

Pancreas;

Sarcomatoid carcinoma;

Undifferentiated;

\section{ABSTRACT}

Undifferentiated carcinoma of pancreas with osteoclastic giant cells is a rare tumor. The prognosis is slightly better than usual anaplastic carcinoma. It is said to have an epithelial origin. We present a case of 61-year-old female who presented with features of cholangitis and on evaluation found to have pancreatic mass. Pancreatic intraepithelial neoplasia was also present in our case, which is a feature less commonly noted in published literature.

\section{Correspondence:}

Dr Lakshmi Priya U, MD

Assistant Professor, Department Of Pathology,

Mes Medical College, Palachode P.O, Perinthalmanna,

Kerala- 679338, India

ORCID ID: 0000-0001-8322-1578

Email:lakshmipriyatirur@gmail.com
Received : January $17^{\text {th }} 2020$; Accepted : March $17^{\text {th }} 2020$

Citation: Priya LU, Babu N P K, Sideeque A. Undifferentiated carcinoma of pancreas with osteoclastic giant cells along with Pan IN in a diabetic female- a case report. J Pathol Nep 2020;10:1685-8 DOI 10.3126/jpn.v10i1.27297

Copyright: This is an open-access article distributed under the terms of the Creative Commons Attribution 4.0 International License, which permits unrestricted use, distribution, and reproduction in any medium, provided the original author and source are credited.

\section{INTRODUCTION}

Undifferentiated carcinoma (anaplastic carcinoma) is a malignant neoplasm in which significant portion of the tumor does not show a definitive direction of differentiation. ${ }^{1}$ A number of terms have been used to describe variants of undifferentiated carcinoma of the pancreas, including pleomorphic carcinoma, pleomorphic giant cell carcinoma, sarcomatoid carcinoma, spindle cell carcinoma, anaplastic carcinoma, undifferentiated carcinoma. ${ }^{1-3}$ Undifferentiated carcinoma with osteoclastic giant cells of the pancreas (UC- OGC) is a distinctive tumor type in the pancreas. It is regarded as a variant of sarcomatoid carcinoma with striking chemotaxis of osteoclastic giant cells. The biologic nature of these tumors is yet to be unravelled. These tumors have been noted to coexist with ductal adenocarcinomas or mucinous cystic neoplasms (MCNs). ${ }^{4}$

\section{CASE REPORT}

A 61-year-old female who is a known case of diabetes mellitus, presented to gastroenterology OPD with 


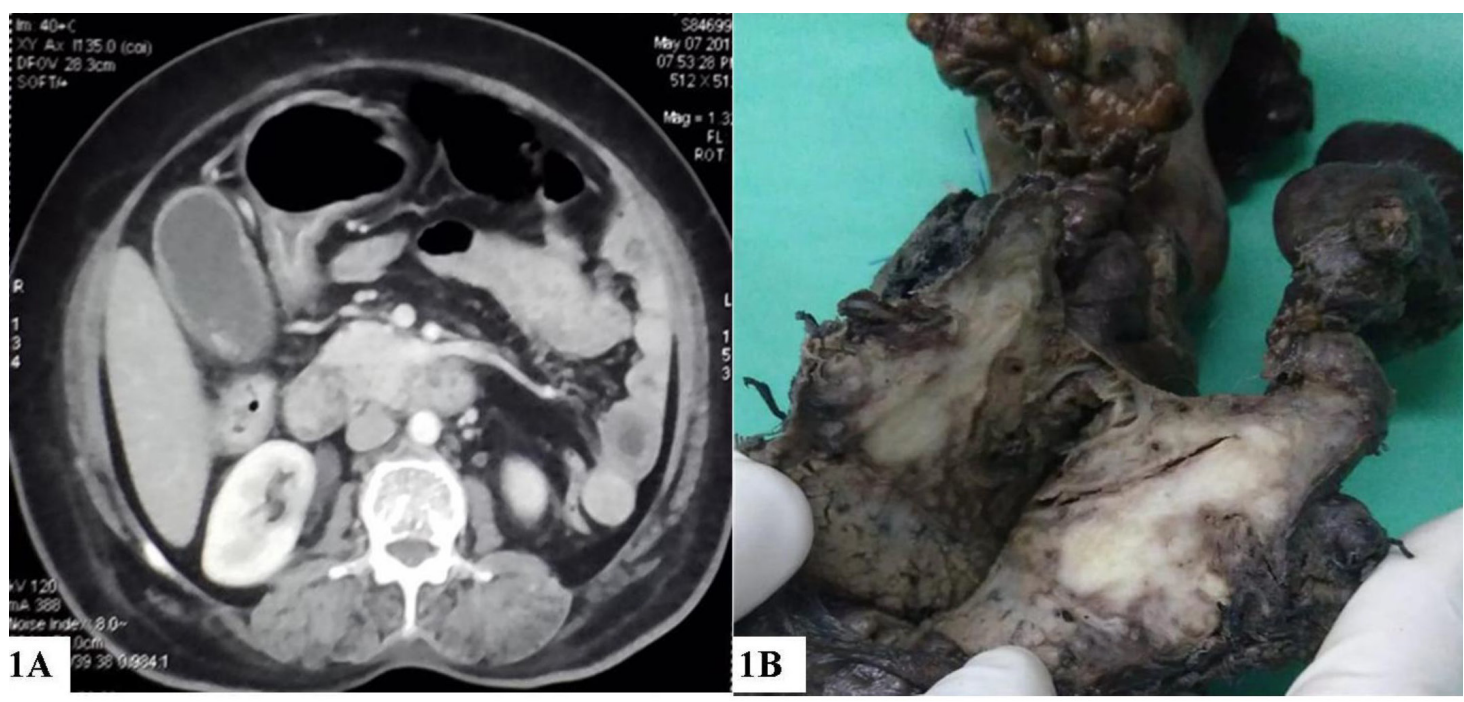

Figure 1: A) CT scan shows a mass lesion in the head and neck of the pancreas B) Whipple resection specimen shows an irregular, infiltrating grey white tumor in the neck of pancreas also extending to the head.

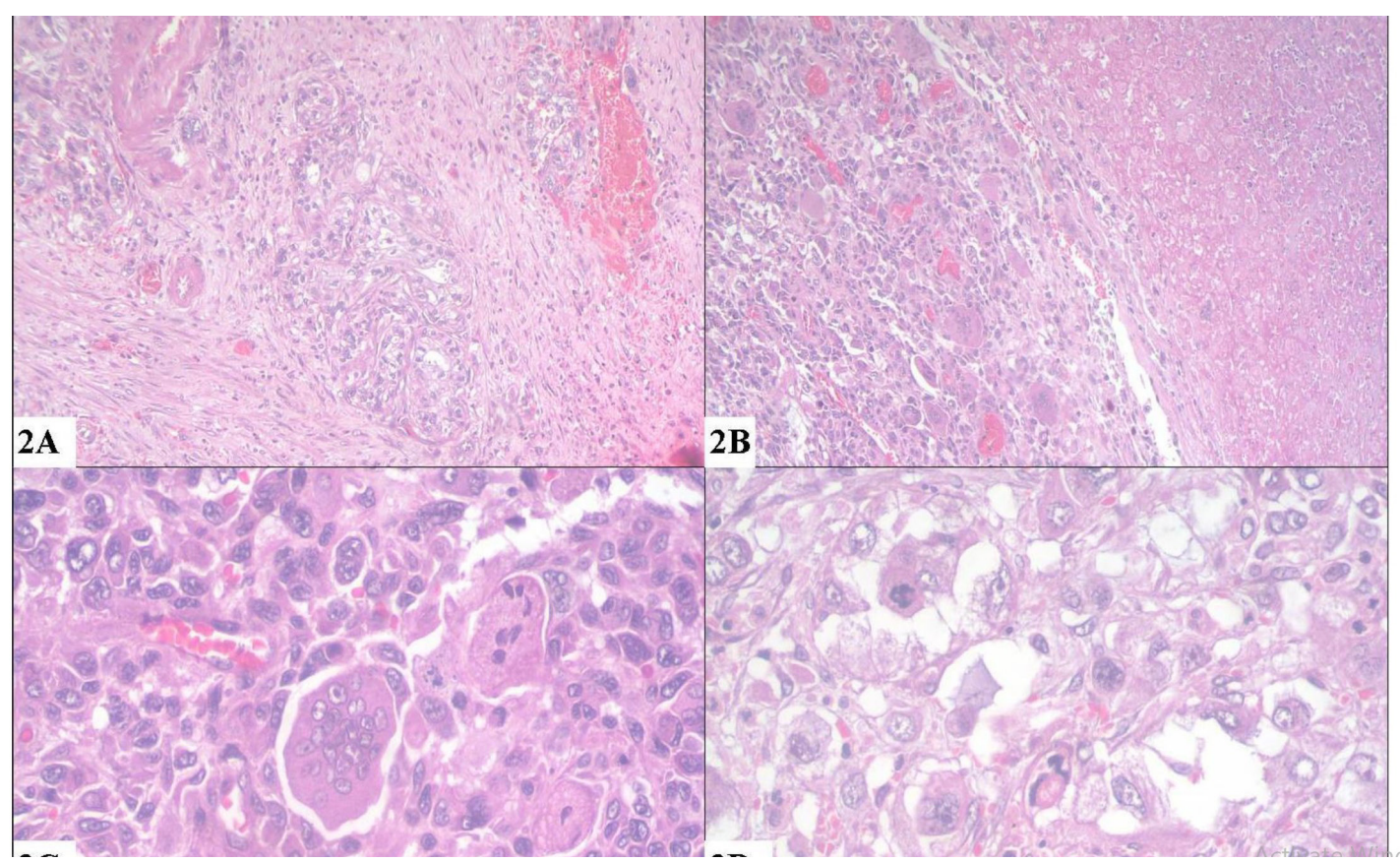

Figure 2: A) Tumour cells arranged as acini and glands (HE stain, X100) B) Sarcomatoid areas with spindle cells and giant cells bordering areas of necrosis and hemorrhage (HE stain, X100) C) Osteoclastic giant cells in higher power (HE stain, X400) D) Tumor cell with marked pleomorphism and atypical mitotic figures (HE stain, X400)

complaints of right hypochondrial pain. Cholangitis was suspected and she underwent ERCP. During the procedure a mass was detected in the pancreas and there was obstruction in the bile duct for which stenting was done. Then she was referred to gastro-surgeon. She was found to have elevated CA19-9(48; $\mathrm{n}<37 \mathrm{U} / \mathrm{mL})$. CT showed an irregular mass lesion in the head of the pancreas (fig. 1A). Whipple resection was planned and intra-operatively tumor was seen involving superior mesenteric artery and seen very close to portal vein. Subsequently we received Whipple resection specimen .An ill-circumscribed, infiltrating grey white mass lesion in the neck of the pancreas extending to the head, measuring $3.5 \times 3 \times 2 \mathrm{~cm}$ (fig. 1B).
Sections showed a tumor (fig. 2A-D) arranged predominantly as sheets and focally as tubules and acini. Extensive areas show undifferentiated component with highly pleomorphic spindle cells/mononuclear cells arranged as sheets. Large areas of necrosis and hemorrhage seen and these areas were bordered by numerous osteoclasts like giant cells many of which had $>20$ nuclei. Many scattered bizarre tumor cells were seen. Mitosis was 8-10/10hpf. Section from pancreatic duct showed pancreatic intraepithelial neoplasia 2 (fig2E and F).

Immunohistochemistry with CK7 and vimentin was done. The epithelial mucinous component and few mononuclear 


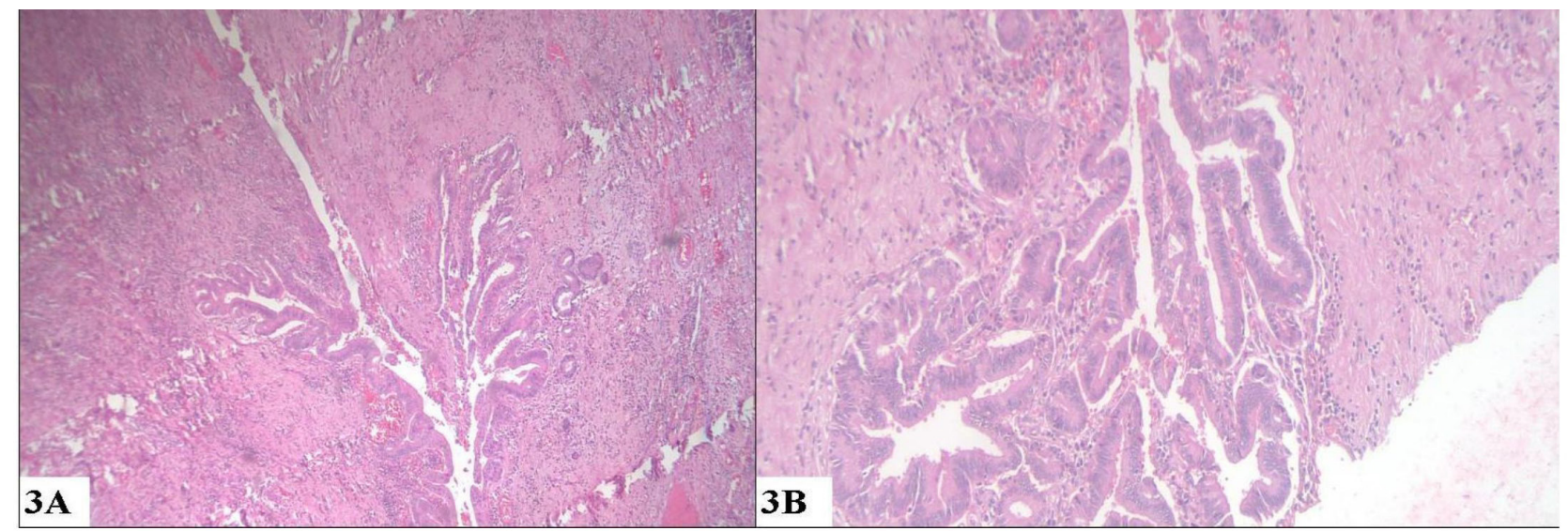

Figure 3: A) Pancreatic duct with papillary infoldings (HE stain, X50); B) Duct lined by cells with stratification, loss of polarity and mild nuclear atypia (HE stain, X100)

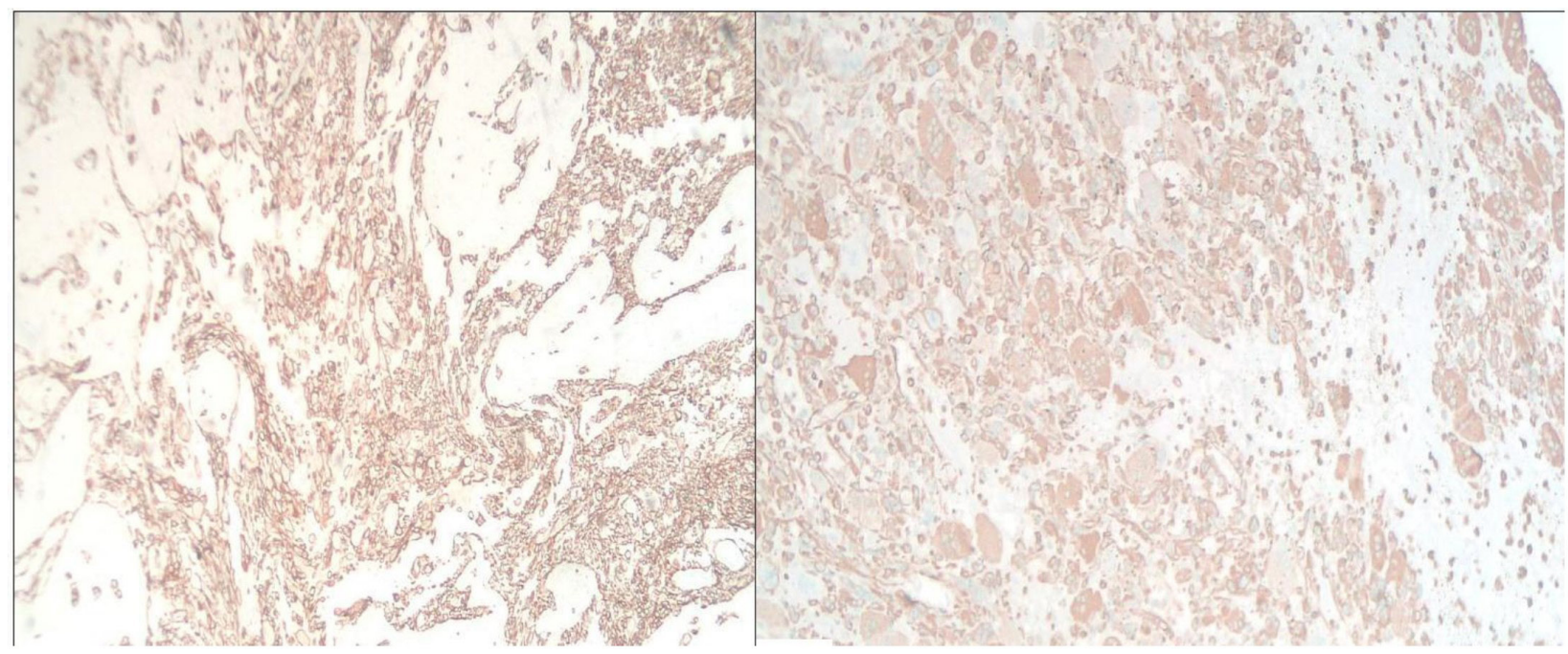

Figure 4: A) Cytokeratin positive in the epithelial and mononuclear cells ; B) Vimentin positive in the mononuclear cells and giant cells

spindle cells showed cytoplasmic positivity. Mononuclear spindle cells and osteoclast like giant cells showed strong cytoplasmic positivity for vimentin (fig. 3).

\section{DISCUSSION}

Undifferentiated pancreatic carcinoma with osteoclast like giant cells was initially described in 1968 by Juan Rosai as a distinct tumor type and a variant of undifferentiated carcinoma defined by conspicuous presence who of giant cells resembling "osteoclastic cells". This tumor is now well recognized as a distinct entity of the pancreas, although it is very rare. ${ }^{4}$ This is a rare neoplasm composed of round to spindle-shaped, highly pleomorphic neoplastic mononuclear cells and large, non-neoplastic multinucleated histiocytic giant cells. ${ }^{1}$ The osteoclast-like giant cells can have increase phagocytic active and may contain haemosiderin.

Pancreatic UC-OGC is more common in middle-aged and elderly patients, $94 \%$ of whom are over 50 years of age, and the average age is 63 years. Most patients are females (male: female $=7: 10$ ). The clinical symptoms are atypical, and mostly manifest as upper abdominal pain and/or weight loss. Loss of appetite, abnormal taste, nausea, steatorrhea, and some other gastrointestinal symptoms have also been reported in some cases. ${ }^{6}$ The neoplasms are mostly located in the body and tail of the pancreas. ${ }^{4,7}$ UC-OGCs are nodular and promote marginal growth. Despite the large volume, tissue infiltration and lymph node metastases are not common. ${ }^{4}$ The prognosis of the tumor is poor and the median survival is only 12 months. ${ }^{1}$

There is much debate in the literature as to the origin of the tumor, with many authors favoring mesenchymal origin, and others favoring epithelial origin. ${ }^{5,8}$ There is overwhelming evidence that the osteoclastic cells in this tumor are indeed osteoclastic cells, both by morphology, as well as immunoprofile (positive for CD68, negative for cytokeratins AE1/AE3 and p53, and had a low Ki-67 index) and thus are believed to be a benign population of 
histocytic cell lineage, that is massively recruited to this distinctive sarcomatoid neoplasm. ${ }^{9}$ It is hypothesized that OGC recruitment is a result of chemotactic factors produced by the neoplastic cells. ${ }^{7}$ Most of the neoplastic mononuclear cells express vimentin, some express keratin and somelabel with antibodies to $\mathrm{p} 53$. In a study by Luchini et al it was purported that UC-OGC's are variants of pancreatic ductal carcinoma (PDC) due to the presence of shared mutations in KRAS and other critical tumor suppressor genes commonly associated with PDC (TP53, CDKN2A and SMAD4). ${ }^{10}$

\section{CONCLUSIONS}

It is important to recognize this entity as it has got slightly better prognosis compared to usual undifferentiated carcinoma. Worldwide further studies may be needed for defining treatment guidelines for this entity. This case had an additional component of Pan IN- 2 also which is a rare association with undifferentiated carcinoma. Our patient expired soon after the diagnosis.

\section{Conflict of Interest: None}

\section{REFERENCES}

1. Bosman FT, Carniero F, Hruban RH, et al. WHO Classification of Tumours of the Digestive System. 4th ed. IARC: Lyon; 2010.

2. Ichikawa T, Federle MP, Ohba S, Ohtomo K, Sugiyama A, Fujimoto $\mathrm{H}$, et al. Atypical exocrine and endocrine pancreatic tumors (anaplastic, small cell and giant cell types): CT and pathologic features in 14 patients. Abdom Imaging 2000;25:409-19. Crossref

3. Paal E, Thompson LD, Frommelt RA, Przygodzki RM, Heffess CS. A clinicopathologic and immunohistochemical study of 35 anaplastic carcinomas of the pancreas with a review of the literature Ann Diagn Pathol 2001;5:129-40. Crossref
4. 4. Muraki T, Reid MD, Basturk O, et al. Undifferentiated carcinoma with osteoclastic giant cells of the pancreas: clinicopathological analysis of 38 cases highlights a more protracted clinical course than currently appreciated. Am J Surg Pathol 2016;40:1203-16. Crossref

5. Sakhi R, Hamza A, Khurram MS, Ibrar W, Mazzara P. Undifferentiated carcinoma of the pancreas with osteoclast-like giant cells reported in an asymptomatic patient: a rare case and literature review. Autops Case Rep 2017;7:51-7. Crossref

6. Rustagi T, Rampurwala M, Rai M, et al. Recurrent acute pancreatitis and persistent hyperamylasemia as a presentation of pancreaticosteoclastic giant cell tumor: an unusual presentation of a rare tumor. Pancreatology 2011;11:12-5. Crossref

7. Sah SK, Li Y, Li Y. Undifferentiated carcinoma of the pancreas with osteoclast-like giant cells: a rare case report and review of the literature Int J Clin Exp Pathol 2015;8:11785-91.

8. Maksymov V, Khalifa MA, Bussey A, Carter B, Hogan M Undifferentiated (anaplastic) carcinoma of the pancreas with osteoclast-like giant cells showing various degree of pancreas duct involvement: a case report and literature review. JOP. 2011;12:170-6. Crossref

9. Westra WH, Sturm P, Drillenburg P, et al. K-ras oncogene mutations in osteoclast-like giant cell tumors of the pancreas and liver: genetic evidence to support origin from the duct epithelium. Am J Surg Pathol.1998;22:1247-54. Crossref

10. Luchini C, Pea A, Lionheart G, et al. Pancreatic undifferentiated carcinoma with osteoclast-like giant cells is genetically similar to, but clinically distinct from, conventional ductal adenocarcinoma. J Pathol 2017;243:148-54. Crossref 